\title{
Practitioner consensus on the determinants of capacity building practice in high-income countries
}

\author{
Elizabeth Swanepoel ${ }^{1, *}$, Ann Fox ${ }^{2}$ and Roger Hughes ${ }^{3}$ \\ ${ }^{1}$ School of Health and Sports Sciences, University of the Sunshine Coast, Locked Bag 4, Maroochydore DC, QLD \\ 4558, Australia: ${ }^{2}$ Department of Nutritional Sciences and the Dalla Lana School of Public Health, University of \\ Toronto, Toronto, Canada: ${ }^{3}$ Faculty of Health Sciences and Medicine, Bond University, Gold Coast, Queensland, \\ Australia
}

Submitted 13 April 2014: Final revision received 6 August 2014: Accepted 2 September 2014: First published online 22 October 2014

\begin{abstract}
Objective: To assess and develop consensus among experienced public health nutrition practitioners from high-income countries regarding conceptualisation of capacity building in practice, and to test the content validity of a previously published conceptual framework for capacity building in public health nutrition practice.

Design: A Delphi study involving three iterations of email-delivered questionnaires testing a range of capacity determinants derived from the literature. Consensus was set at $>50 \%$ of panellists ranking items as 'very important' on a five-point Likert scale across three survey rounds.

Setting: Public health nutrition practice in Australia, the UK, Canada and the USA. Subjects: Public health nutrition practitioners and academics.

Result: A total of thirty expert panellists (68\% of an initial panel of forty-four participants) completed all three rounds of Delphi questionnaires. Consensus identified determinants of capacity building in practice including partnerships, resourcing, community development, leadership, workforce development, intelligence and quality of project management.

Conclusions: The findings from the study suggest there is broad agreement among public health nutritionists from high-income countries about how they conceptualise capacity building in public health nutrition practice. This agreement suggests considerable content validity for a capacity building conceptual framework proposed by Baillie et al. (Public Health Nutr 12, 1031-1038). More research is needed to apply the conceptual framework to the implementation and evaluation of strategies that enhance the practice of capacity building approaches by public health nutrition professionals.
\end{abstract}

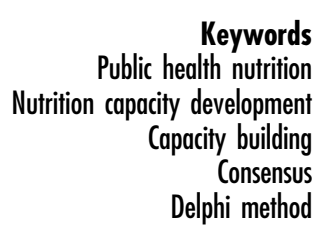

Building capacity is a strategy and approach well known and widely applied in developing world public health nutrition practice $^{(1)}$. As a concept and a term used in public health nutrition practice contexts worldwide, it is a term used somewhat ambiguously however ${ }^{(1-3)}$. For the purpose of the present paper and consistent with earlier definitions, capacity building in the context of public health nutrition practice is defined here as intentional actions by practitioners designed to enhance the ability of a community to mobilise effective responses to public health nutrition problems. This definition situates the practitioner as a central agent for capacity building in communities and capacity building approaches at the heart of public health nutrition practice. This is consistent with previously identified consensus about the core functions of public health nutrition practice ${ }^{(4)}$.
Public health nutrition practice in high-income countries is likely to vary considerably from that in low- and middleincome countries, particularly in the context of practice relating to capacity building. The lack of reference to capacity building as a construct, a strategy or an approach to practice in the public health nutrition intervention literature in high-income countries reinforces earlier observations that capacity building is largely invisible in practice $^{(5)}$ and a concept that is ambiguously applied ${ }^{(6)}$. It is possible that capacity building requires greater application of, and integration in, public health nutrition practice in developed countries to improve the effectiveness and sustainability of interventions ${ }^{(2)}$.

Capacity building has been identified as a key enabler of sustainability, ensuring that public health interventions and the effects of those interventions are sustained ${ }^{(2,7)}$. 
The present study assumes that integration of capacity building approaches into practice will logically result in more effective promotion and maintenance of the nutrition-related health and well-being of populations and communities.

In order to assist this integration of capacity building strategies and approaches in practice, a conceptual framework was proposed based on the capacity building literature in other fields ${ }^{(2)}$. This framework suggested eight determinants of capacity for effective nutrition intervention that provide a focus for development. These determinants of capacity include: leadership; resourcing; intelligence; community development; partnerships; organisational development; workforce development; and project management quality ${ }^{(2)}$. As a conceptual device, this framework is limited if it does not have content validity and adequately reflect public health nutritionists' understanding or experience of the concept of capacity building in practice.

In the present study, determinants are defined as the key factors that underpin capacity to achieve public health nutrition goals and objectives in practice. Intervention planning in public health practice is premised on the logic that interventions address determinants of a problem, aiming to change determinants so that the effects of this change flow through to changes in nutrition or health outcomes. The development and evaluation of capacity building strategies in practice should similarly apply this logic ${ }^{(2)}$, requiring consideration of capacity determinants to clarify conceptualisations of capacity building as a practice approach. Although there has been much activity in documenting the general determinants of capacity development ${ }^{(8)}$, there appears to be limited literature detailing the organisation and makeup of the broad determinants that contribute to capacity building for public health nutrition practice, particularly in a developedcountry practice context where capacity building appears to be largely ignored. Few researchers have described in depth the sub-determinants that contribute to each of the broad determinants of capacity building.

The present study used a consensus development approach (Delphi technique) to assess and develop consensus on practitioner conceptualisations of capacity building in practice within a group of experienced public health nutrition practitioners from high-income countries, and to determine the content validity of a previously suggested capacity building conceptual framework ${ }^{(2)}$.

\section{Methods}

\section{The Delphi technique}

The aim of a Delphi study is to determine the extent to which experts agree about a given issue ${ }^{(9)}$; the technique can be applied to both the measurement and development of consensus ${ }^{(10)}$. This method is characterised by four main features including anonymity of participants from other participants, iteration via several rounds of questionnaires, controlled feedback between rounds and the use of statistical group response ${ }^{(11,12)}$. Consensus occurs because the views of the participants converge through a process of informed decision making ${ }^{(13)}$. It has previously been used to develop consensus on definitions for public health nutrition, as well as competencies for effective public health nutrition practice ${ }^{(4,14,15)}$. The Delphi process has also been identified as an effective means to validate assessment tools, instruments and classification systems in other health disciplines through input of experts ${ }^{(16-18)}$.

\section{Literature review}

A non-exhaustive review of the literature and previously published capacity building models ${ }^{(2,8,19-22)}$ was summarised and provided to participants as background information. This literature review revealed a suite of twenty-two capacity determinants that were described for Delphi panellists as represented in the literature and tested in the Delphi surveys.

\section{Participant recruitment}

There is no standard method for selecting experts or deciding who should be included in a Delphi study. Purposive sampling (the deliberate selection of cases that will be able to provide rich or in-depth information about the issue being examined ${ }^{(23)}$ ) was used to recruit people with high-level knowledge and experience in public health nutrition practice from developed English-speaking nations with well-developed and described workforces $^{(24-27)}$ (Australia, Canada, the USA and the UK). The rationale for recruiting English-speaking professionals was to reduce any language-related ambiguity that may have arisen from misinterpretation of the survey rounds. Public health nutritionists representing nations with developed public health nutrition workforces were selected to ensure panellists had a common practice background and were all working within a similar context.

Existing professional networks in these countries were selected as a convenient avenue for recruiting participants. The networks included, namely the Dietitians Association of Australia Public Health and Community Nutrition Special Interest Group (Australia), The Nutrition Society Public Health Nutrition Register (UK), the Ontario Society of Nutrition Professionals in Public Health (Canada) and the Association of Territory and State Public Health Nutrition Directors (USA), were used as sample frames for the email delivery of an invitation to participate in the study. The invitation clearly articulated that the study was looking to recruit experts in the field of public health nutrition, facilitating self-selection of public health nutrition experts.

The study was conducted according to the guidelines laid down in the Declaration of Helsinki and all procedures involving human participants were approved by 
Griffith University and the University of Toronto ethics committees. Written informed consent was obtained from all participants.

\section{Survey process}

The Delphi study consisted of three rounds of electronic questionnaires, with the focus of each questionnaire presented in Fig. 1. The first-round questionnaire was circulated to panellists along with background information and instructions for completion of the survey. The first-round questionnaire requested quantitative rankings of importance of determinants on a Likert scale, and also offered panellists the opportunity to suggest additional determinants of capacity building that were not already listed. A modified version of the first-round questionnaire, including the dispersion of ratings for each of the quantitative questions rated on the Likert scale, was then redistributed to participants in round 2. Similarly, the third-round questionnaire was a modified version of the second and included the dispersion ratings from round 2 . In rounds 2 and 3, panellists ranked the importance of a more extensive list of determinants of capacity building. All background information, literature summary, questionnaires and feedback were sent to participants via email. Similarly, the panellists returned their responses to the researcher using this medium.

\section{Defining consensus}

Two types of consensus have been identified and used in the present study: majority consensus and stability consensus. Majority consensus involves a certain proportion of the panellists being in agreement. Stability consensus is based on the consistency of responses, or by a lack of variation between responses from one round to the next $^{(12)}$. A reduction in variability of panellists' responses over the rounds is indicative of greater stability, suggesting that consensus has been achieved. In the present study, the authors arbitrarily defined majority consensus as greater than $50 \%$ of respondents ranking items as "very important' on the five-point Likert scale. Stability consensus was considered achieved if response variability between rounds was less than $10 \%$, or if responses consistently moved in a positive or negative direction over the questionnaire rounds.

All of the determinants assessed were drawn from the capacity development literature and as such were rated to

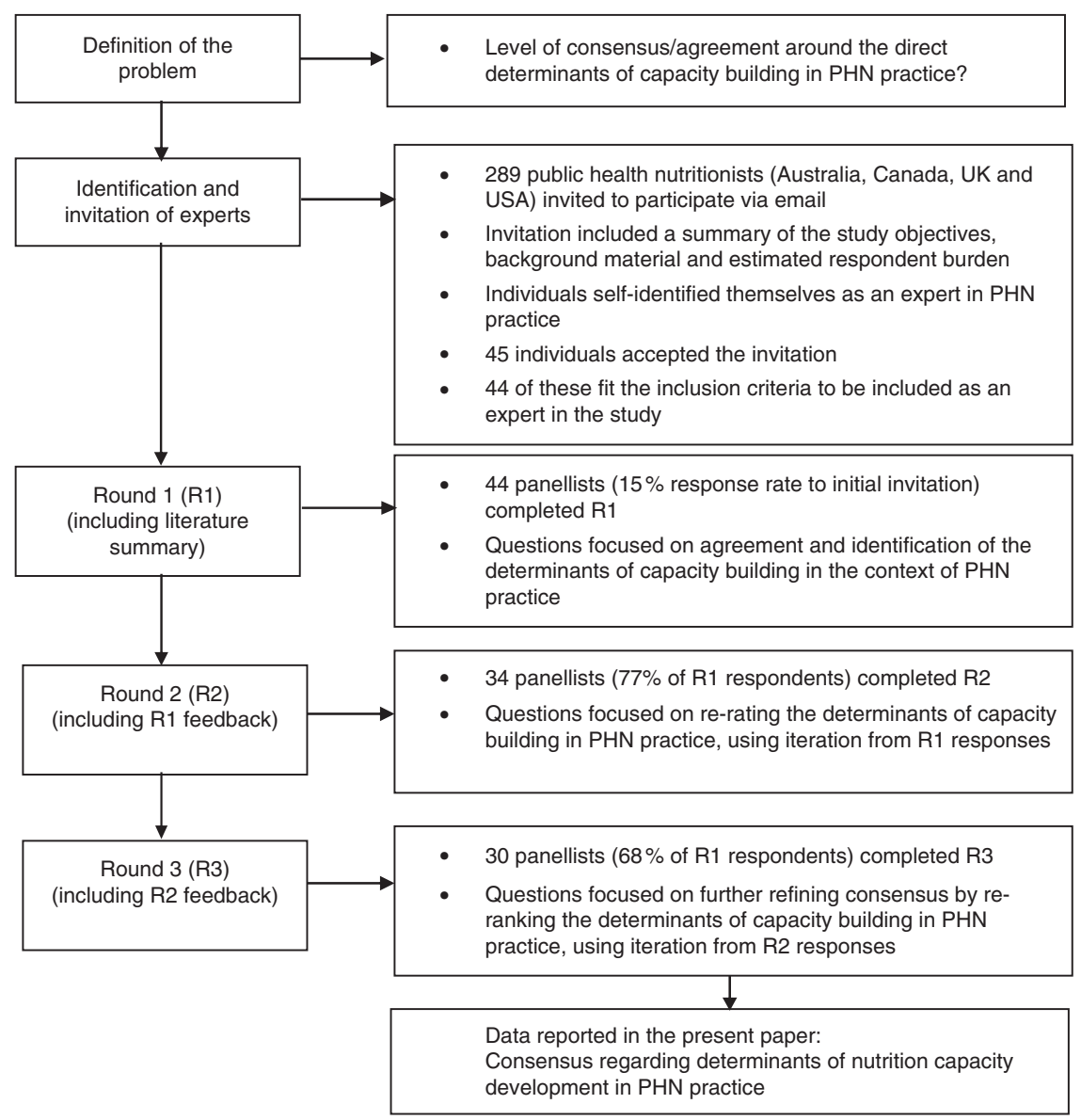

Fig. 1 Schematic depiction of the Delphi process (PHN, public health nutrition) 
some degree by panellists as 'important'. In order to differentiate between the levels of importance, and identify those with the most support, only the 'very important' ratings have been included in the presentation of these results. It was also evident that as the rounds progressed and expert consensus for the highest-ranked determinants increased, those determinants that were rated as less important tended to lose support. Across the three rounds stability consensus was evident, with the ranking of most determinants consistently moving in a positive direction or a negative direction, and as such a fourth round of questionnaires was deemed unnecessary.

\section{Data analysis}

This Delphi study collected quantitative data as well as qualitative suggestions of alternative determinants of capacity building in public health nutrition practice. Although panellists had the option to put forward additional determinants, no panellists opted to do so, and as such the same twenty-two determinants were tested over all three rounds of questionnaires. Data from all three survey rounds were entered into the statistical software package SPSS version $17 \cdot 0$ for frequency of response distributions. The $\chi^{2}$ test was conducted to determine differences between the attributes of panellists completing all three rounds of questionnaires compared with those completing only the first round. The level of significance was taken as $P<0 \cdot 05$.

\section{Results}

\section{Description of the expert panel}

The initial invitation to participate yielded a response rate of $15 \%$ ( $n$ 44). Approximately $68 \%$ of the initial panel completed the three survey rounds of the Delphi study. Maintaining 50 to $80 \%$ of participants is reported as a typical rate of complete participation in a Delphi study ${ }^{(28)}$. The distribution of panellists and attrition over the three rounds are illustrated in Table 1. The final expert panel was made up of those participants who responded to all three rounds of the Delphi study ( $n$ 30). A description of the attributes of the expert panel $(n$ 30) is presented in Table 1 . Twenty-four of the participants agreed to being recognised and named as an expert panellist (see Acknowledgements).

The $\chi^{2}$ analysis of participants' attributes indicated that there was no significant difference in the proportion of academics $v$. practitioners $\left(\chi^{2}=2 \cdot 47, P=0 \cdot 12\right)$ or higher qualification level $\left(\chi^{2}=1.45, P=0.23\right)$ between rounds 1 and 3. More experienced practitioners (i.e. $>10$ years) were significantly more likely to complete all three rounds of questionnaires than less experienced practitioners $\left(\chi^{2}=3 \cdot 85, P=0.05\right)$.

\section{Determinants of capacity building in public bealth nutrition practice}

Panellists were asked to rank the importance of each of the twenty-two determinants contributing to capacity building in public health nutrition practice on a five-point Likert scale. Table 2 presents the proportion of respondents who rated each determinant as 'very important' from round 1 ( $n$ 44) to round 3 ( $n$ 30); the determinants are listed in order of greatest to least importance. While the strong majority consensus for determinants is clear from these results, there appears to be considerable instability in consensus after three Delphi rounds (with subsequent ratings across rounds moving to greater majority consensus).

The results of the second- and third-round rankings of determinants are summarised in Table 3 and organised against the conceptual framework previously proposed ${ }^{(2)}$.

Determinants from the conceptual framework proposed by Baillie $e t a l{ }^{(2)}$ that achieved majority consensus with the expert panel have been indicated in bold in Table 3 . To illustrate the variation in responses, the last column in Table 3 presents the percentage shift in determinant ratings from round 2 to round 3 (stability consensus). A positive percentage shift implies there is increasing support for that determinant and a negative percentage shift indicates the support for that determinant has lessened from round 1 to round 3. A smaller percentage shift

Table 1 Description of the attributes of the expert panel

\begin{tabular}{|c|c|c|c|c|c|c|c|c|c|}
\hline \multirow[b]{2}{*}{ Country } & \multicolumn{3}{|c|}{$\begin{array}{l}\text { Attrition over three } \\
\text { rounds }\end{array}$} & \multicolumn{2}{|c|}{$\begin{array}{l}\text { Current position of expert } \\
\text { panel }(n 30)\end{array}$} & \multicolumn{2}{|c|}{$\begin{array}{l}\text { Qualifications of expert } \\
\text { panel }(n 30)\end{array}$} & \multicolumn{2}{|c|}{$\begin{array}{c}\text { Years of experience of expert } \\
\text { panel }(n 30)\end{array}$} \\
\hline & $\mathrm{R} 1(n)$ & $\mathrm{R} 2(n)$ & $\mathrm{R} 3(n)$ & Academic & Practitioner & Entry level & $>$ Entry level $^{*}$ & $2-10$ years & $>10$ years \\
\hline Australia & 15 & 10 & 10 & 4 & 6 & 3 & 7 & 0 & 10 \\
\hline UK & 8 & 6 & 6 & 3 & 3 & 1 & 5 & 1 & 5 \\
\hline Canada & 12 & 11 & 9 & 0 & 9 & 3 & 4 & 2 & 6 \\
\hline USA & 9 & 7 & 5 & 1 & 4 & 2 & 3 & 1 & 4 \\
\hline Total & 44 & 34 & 30 & 8 & 22 & 9 & 19 & 4 & 25 \\
\hline
\end{tabular}

R1, round 1; R2, round 2; R3, round 3 .

*'> Entry level' qualifications is further study that has been completed beyond that which is minimally required to practice as an entry-level public health nutritionist (e.g. PhD). 
Table 2 Percentage of panellists ranking determinants as 'very important' from round 1 ( $n 44$ and $n 30$ ) to round 3 ( $n$ 30), with percentage shift between rounds 1 and $3^{*}$

\begin{tabular}{|c|c|c|c|c|}
\hline \multirow[b]{2}{*}{ Determinant } & \multirow{2}{*}{$\frac{\text { Initial panel }}{\mathrm{R} 1(n 44)}$} & \multicolumn{3}{|c|}{ Final panel } \\
\hline & & $\mathrm{R} 1(n 30)$ & $\mathrm{R} 3(n 30)$ & Shift (R1 to R3) \\
\hline Partnerships & 73 & 70 & 97 & +27 \\
\hline Human resources & 69 & 73 & 97 & +24 \\
\hline Critical reflection in practice & 56 & 47 & 90 & +43 \\
\hline Leadership & 68 & 72 & 83 & +11 \\
\hline Workforce competencies and preparedness & 64 & 62 & 83 & +21 \\
\hline Problem solving & 62 & 70 & 79 & +9 \\
\hline Community participation & 69 & 67 & 77 & +10 \\
\hline Knowledge transfer & 58 & 57 & 77 & +20 \\
\hline Needs assessment & 62 & 57 & 73 & +16 \\
\hline Quality of project management & 49 & 47 & 61 & +14 \\
\hline Workforce size and composition & 51 & 60 & 60 & 0 \\
\hline Networks & 57 & 55 & 47 & -8 \\
\hline Resource mobilisation & 56 & 60 & 38 & -22 \\
\hline Financial funding & 42 & 43 & 37 & -6 \\
\hline Asking why & 52 & 52 & 30 & -22 \\
\hline Professional organisational development & 48 & 41 & 17 & -24 \\
\hline Sense of community & 46 & 41 & 17 & -24 \\
\hline Community power & 42 & 40 & 17 & -23 \\
\hline Outside agents & 27 & 20 & 7 & -13 \\
\hline Local organisational structures & 38 & 40 & 3 & -37 \\
\hline Community values & 29 & 23 & 3 & -20 \\
\hline Physical infrastructure & 9 & 7 & 0 & -7 \\
\hline
\end{tabular}

$\mathrm{R} 1$, round $1 ; \mathrm{R} 3$, round 3 .

*Determinants in bold have gained majority consensus, which is defined as $>50 \%$ of panellists rating the determinant as 'very important'.

suggests less variation in responses and a greater level of expert consensus. Eleven determinants gained majority consensus and were identified as having the most significant contribution to building capacity in public health nutrition practice. These eleven determinants have been indicated in bold in Table 2 and include partnerships, human resources, critical reflection in practice, leadership, workforce competencies and preparedness, problem solving, knowledge transfer, community participation, needs assessment, quality of project management, and workforce size and composition.

The second aim of the study was to test the content validity of the capacity building conceptual framework with experts in a public health nutrition practice context. Table 3 demonstrates that many of the determinants tested in this Delphi study can be organised to be consistent with the conceptual model previously proposed by Baillie et $a l^{(2)}$.

\section{Discussion}

The literature describes capacity building as being invisible and subconscious in practice ${ }^{(5)}$, which may help explain why capacity building approaches to public health nutrition practice in developed countries do not seem to have adopted this tradition which situates capacity building as central to practice. More recently, a capacity building narrative has been reintroduced in the field of public health nutrition in an attempt to focus professional awareness $^{(1)}$, with several studies focusing on diet, physical activity and appropriate weight gain in childhood basing their design on a capacity building approach ${ }^{(29-31)}$. These studies have intentionally adopted and integrated principles of capacity building into the intervention design, delivery and evaluation.

The present Delphi study aimed to understand conceptualisations of capacity building in practice from the perspectives of public health nutrition practitioners in developed countries, as well as to test the content validity of an earlier conceptual framework for capacity building proposed for more effective public health nutrition practice $^{(2)}$. In doing so, we hoped to clarify capacity building as a practice construct and reduce any ambiguity associated with the term. Enhancing conceptual clarity about capacity building in practice should help inform practitioner uptake of a capacity building approach in everyday practice.

A more thorough understanding of the determinants of capacity building in public health nutrition practice can be gained by making comparisons between the results of the Delphi study and the determinants previously identified in the conceptual framework ${ }^{(2)}$. Table 3 illustrates that there is sound agreement between the conceptual framework and Delphi panellists' understanding of the determinants of capacity development in public health nutrition practice. This agreement about the determinants suggests robust content validity of Baillie et al.'s conceptual framework.

Findings from the Delphi study also provide a more complete appreciation of the components of each of the individual capacity building determinants. In particular, 
Table 3 Second- and third-round rankings of determinants organised according to the conceptual framework for capacity development in public health nutrition practice ${ }^{(2)}(n 30)$

\begin{tabular}{|c|c|c|c|c|c|}
\hline \multirow[b]{2}{*}{$\begin{array}{l}\text { Determinant from } \\
\text { Baillie et al. }{ }^{(2)}\end{array}$} & \multirow[b]{2}{*}{ Sub-determinant } & \multirow[b]{2}{*}{ Description of sub-determinant } & \multicolumn{3}{|c|}{$\begin{array}{l}\text { \% rating as 'very } \\
\text { important' }\end{array}$} \\
\hline & & & $\mathrm{R} 2$ & R3 & $\begin{array}{c}\text { Shift } \\
\text { (R2 to R3) }\end{array}$ \\
\hline \multirow[t]{5}{*}{ Leadership } & Organisation & Organisational leadership & 73 & 83 & 10 \\
\hline & Workforce & Leadership from the PHN workforce & 64 & 77 & 13 \\
\hline & Community & Leadership coming from within the target community & 57 & 63 & 6 \\
\hline & Political & Local, state or federal government leadership & 43 & 53 & 10 \\
\hline & Project & Project, programme or intervention leadership & 67 & 43 & -24 \\
\hline \multirow[t]{10}{*}{ Intelligence } & Asking why & $\begin{array}{l}\text { Ability to critically assess the causes that contribute to the } \\
\text { problem/issue }\end{array}$ & 77 & 90 & 13 \\
\hline & Target group consultation & Thorough consultation with the target market & 73 & 90 & 17 \\
\hline & Communication & $\begin{array}{l}\text { Open and fluent methods of communication to enable transfer of } \\
\text { knowledge }\end{array}$ & 83 & 90 & 7 \\
\hline & Monitoring & $\begin{array}{l}\text { Ongoing evaluation of interventions in order to revise and modify } \\
\text { accordingly }\end{array}$ & 80 & 87 & 7 \\
\hline & Evidence-based practice & $\begin{array}{l}\text { Reflecting on previous experiences and evidence to inform future } \\
\text { strategy development }\end{array}$ & 70 & 80 & 10 \\
\hline & Evaluation & Systematic assessment of the outcome of the intervention & 73 & 80 & 7 \\
\hline & Partnerships & Build relationships to enable flow of information between partners & 53 & 76 & 23 \\
\hline & Needs assessment & $\begin{array}{l}\text { Investing time and resources at a formative stage to ensure } \\
\text { greater understanding of the problem/issue }\end{array}$ & 57 & 75 & 15 \\
\hline & Review of the evidence & $\begin{array}{l}\text { Review of literature and scientific evidence relevant to the } \\
\text { problem/issue }\end{array}$ & 56 & 70 & 14 \\
\hline & $\begin{array}{l}\text { Links between academics } \\
\text { and practitioners }\end{array}$ & $\begin{array}{l}\text { Building links to enable transfer of knowledge between academic } \\
\text { and practice settings }\end{array}$ & 53 & 40 & -13 \\
\hline \multirow[t]{6}{*}{ Partnerships } & Communication & Frequent, open lines of communication & 77 & 97 & 20 \\
\hline & Outside agents & Key stakeholders outside the direct project group & 71 & 77 & 6 \\
\hline & Networks & Less formal partnerships such as alliances and coalitions & 53 & 67 & 14 \\
\hline & Shared vision & All partners have the same purpose and direction & 34 & 27 & -7 \\
\hline & Resource exchange & Sharing of resources between partners & 23 & 17 & -6 \\
\hline & Membership & Membership size and diversity of skills & 13 & 13 & 0 \\
\hline \multirow[t]{8}{*}{$\begin{array}{l}\text { Quality of project } \\
\text { management }\end{array}$} & Stakeholder engagement & $\begin{array}{l}\text { Engagement with stakeholders when making decisions relating } \\
\text { to planning, implementation and evaluation of the project }\end{array}$ & 80 & 97 & 17 \\
\hline & Evaluation & Monitor the progress and final outcome of the project. & 70 & 87 & 17 \\
\hline & Target group identification & $\begin{array}{l}\text { Identification of the target group to focus consultation and } \\
\text { community engagement efforts }\end{array}$ & 67 & 83 & 16 \\
\hline & $\begin{array}{l}\text { Practice wisdom and } \\
\text { experience }\end{array}$ & $\begin{array}{l}\text { The knowledge and skills of practitioners that is drawn from their } \\
\text { experiences or observations when working in a particular area }\end{array}$ & 63 & 83 & 20 \\
\hline & Decision making & Decision-making ability & 67 & 82 & 15 \\
\hline & $\begin{array}{l}\text { Knowledge, skills and } \\
\text { abilities of the workforce }\end{array}$ & $\begin{array}{l}\text { The extent to which the workforce is equipped with the } \\
\text { knowledge, skills and abilities to deal with the specific problem } \\
\text { or issue }\end{array}$ & 57 & 60 & 7 \\
\hline & Delegating & Being able to delegate appropriate tasks to others & 43 & 47 & 4 \\
\hline & Goal setting & An ability to set SMART goals and objectives & 43 & 41 & -2 \\
\hline \multirow{4}{*}{$\begin{array}{l}\text { Workforce } \\
\text { development }\end{array}$} & Composition & Skills and competencies of the workforce & 93 & 90 & -3 \\
\hline & Competencies & Relevant training and experience of staff & 77 & 90 & 13 \\
\hline & Skill development & $\begin{array}{l}\text { Opportunities that staff have to engage in professional } \\
\text { development }\end{array}$ & 73 & 83 & 10 \\
\hline & Size & $\begin{array}{l}\text { Size of the workforce in terms of number of practitioners } \\
\text { employed and hours worked }\end{array}$ & 30 & 20 & -10 \\
\hline \multirow{7}{*}{$\begin{array}{l}\text { Community } \\
\text { development }\end{array}$} & Implementation & Involvement of the community in implementing strategies & 60 & 77 & 17 \\
\hline & Planning involvement & Community participation in planning PHN interventions & 62 & 83 & 21 \\
\hline & Service use & Community participation in services or strategies & 53 & 77 & 24 \\
\hline & Problem identification & Community identify the PHN problem & 63 & 73 & 10 \\
\hline & Strategy identification & Involvement of the community in identifying suitable strategies & 57 & 70 & 13 \\
\hline & Concern & Level of concern with the target community's issues & 33 & 17 & -16 \\
\hline & Connectedness & Sense of connection with the target community & 30 & 20 & -10 \\
\hline \multirow[t]{3}{*}{ Resources } & Resource mobilisation & $\begin{array}{l}\text { Gathering resources from other sectors as well as from within the } \\
\text { community itself }\end{array}$ & 21 & 38 & 17 \\
\hline & Financial funding & The level of financial or monetary support invested & 40 & 37 & -3 \\
\hline & Physical infrastructure & May include physical resources such as buildings and equipment & 3 & 0 & -3 \\
\hline \multirow[t]{2}{*}{$\begin{array}{l}\text { Organisational } \\
\text { development }\end{array}$} & $\begin{array}{l}\text { Professional organisational } \\
\text { development }\end{array}$ & $\begin{array}{l}\text { The structures, processes and management systems that enable } \\
\text { public health nutrition organisations to function effectively }\end{array}$ & 18 & 17 & -1 \\
\hline & $\begin{array}{l}\text { Local organisational } \\
\text { structures }\end{array}$ & $\begin{array}{l}\text { Small groups within a community such as committees, church } \\
\text { and youth groups }\end{array}$ & 3 & 3 & 0 \\
\hline
\end{tabular}

R2, round 2; R3, round 3; PHN, public health nutrition; SMART, specific, measurable, achievable, relevant and time-bound. 
intelligence (referring to information from various sources that can guide effective and systematic public health nutrition strategy development and problem resolution $^{(32)}$ ) was identified as a determinant of capacity building in the conceptual framework. The result of the Delphi study supports this and additionally reveals that intelligence comprises several components including needs assessment, knowledge transfer, critical reflection in practice and problem solving.

Resourcing was not agreed upon by participants as an important determinant of capacity building. Interestingly, human resources were perceived by panellists to be more important than financial funding. Although financial funding was deemed to be important, it did not reach a level of majority consensus and actually encountered a consistent negative shift (stability consensus) losing panellists' support across the three rounds of questionnaires (see Table 2). Projects have access to a variety of resources, with financial funding comprising only one element of this. Additionally project resources can include staff support, influence with policy makers, physical space or infrastructure, skills or knowledge, and personnel ${ }^{(33)}$. This suggests panellists' experience would indicate that improving human resources through investment in workforce development is of greater importance to building capacity than funding dollars alone.

As previously stated, organisational development did not reach a level of majority consensus support by the panel of public health nutritionists in the present study. Organisational development received little support from panellists and a consistent negative shift across the three rounds of questionnaires, indicating increasing consensus for it not to be included as a determinant of capacity development (see Table 3). Although previous literature supports organisational development as a determinant of capacity building ${ }^{(19,34)}$, these findings bring uncertainty as to whether organisational development plays the same role in a practical setting. It is possible that organisational development overlaps with other determinant categories, contributing to construct redundancy.

These findings raise the question as to whether resources and organisational development should be included in the conceptual framework as key determinants of capacity development in public health nutrition practice. Application of the conceptual framework in a practice setting, with feedback from public health nutritionists, is needed for refinement of the framework.

The present study provides a framework to guide public health nutrition practice and develop strategies that address and integrate capacity building in practice, and offer a shared language for capacity building public health nutrition practice. This framework encourages practitioners to consider determinants of capacity individually when designing public health nutrition interventions. It is however recognised that although expert agreement on the theoretical determinants of capacity building can be used to inform practice, further application of a capacity building approach using the conceptual framework is required in the practice setting. Initial validation of the capacity building conceptual framework using the Delphi technique is not the end of the validation process; application of the conceptual framework in practice and continued refinement through practitioner feedback is needed.

\section{Study limitations}

These study findings must be considered relative to the limitations of the consensus development method used. Attempts were made to recruit a panel of public health nutrition experts from four developed English-speaking nations. The panellists included in the study were all active practitioners, researchers or public health nutrition academics, and each self-identified himself/herself as an expert in the field. As such, the results of this consensus study are valuable, however may not represent the views of all public health nutritionists. Additionally, these results may not represent the truth; it is purely a depiction of current consensus and agreement about how this sample conceptualises capacity building in practice. It is also unknown why panellists modified their ratings as the rounds progressed, but the method presumes that panellists change ratings based on iterative feedback about other panellists' views. There was no opportunity to provide an explanation for changing a rating, which limits assessment of this presumption. It should also be noted that the results of the study are indicative of the needs of high-income countries with developed public health workforces, and as such the findings may not be transferrable to low- or middle-income nations. Further studies involving methods that allow for more in-depth exploration of how practitioners apply and interpret capacity building as a construct relevant to practice are required.

\section{Conclusions}

Building capacity as a function of public health nutrition practice needs to become more explicit and less invisible ${ }^{(5)}$. The present study assessed consensus about how capacity building is perceived in the field of public health nutrition practice in high-income countries. Of the twentytwo determinants tested, majority consensus was achieved for eleven key determinants of capacity building which validated six of eight determinants in the conceptual framework previously proposed by Baillie et $a l .{ }^{(2)}$. A better understanding of capacity building as a public health strategy in itself may enable it to be more routinely incorporated into daily practice. Further work needs to be invested in developing effective methods to inform and evaluate capacity building strategies in public health nutrition practice. 


\section{Acknowledgements}

Acknowledgements: The following exemplar public health nutritionists completed all three rounds of the Delphi study and have agreed to be recognised as part of the expert panel: Becky Adams, Gill Cowburn, Jennifer Davies, Kerith Duncanson, Vicki Edwards, Denise Ferris, Crystelle Fogle, Christine Innes, Anka Johnston, Sharon Laurence, Claire Lechner, Julie Lenk, Cyndie MacNeil, Landon Norton, Claire Palermo, Claire Pettinger, Roy Price, Janice Sangster, Rosmary Stanton, Heather Thomas, Rachel Thompson, Marie Traynor, Daniel Warm and Peter Williams. Their contribution, as well as the contributions of those panellists who elected not to be publicly acknowledged, is greatly appreciated. Financial support: This research received no specific grant from any funding agency in the public, commercial or not-for-profit sectors. Conflict of interest: None. Authorship: E.S. designed and implemented the Delphi study as part of her doctorate studies. She had a principal role in methods design, data analysis and reporting. R.H. conceptualised the study and had a principal role in methods design and data analysis. A.F. contributed to study design and data analysis. All authors contributed to the drafting and final editing of the manuscript. Ethics of human subject participation: Ethical approval was obtained from Griffith University and the University of Toronto.

\section{References}

1. Shrimpton R, Hughes R, Recine E et al. (2014) Nutrition capacity development: a practice framework. Public Health Nutr 17, 682-688.

2. Baillie E, Bjarnholt C, Gruber M et al. (2009) A capacity building conceptual framework for public health nutrition practice. Public Health Nutr 12, 1031-1038.

3. Sodjinou R, Fanou N, Deart L et al. (2014) Region-wide assessment of the capacity for human nutrition training in West Africa: current situation, challenges, and way forward. Glob Health Action 7, 23247.

4. Jonsdottir S, Hughes R, Thorsdottir I et al. (2011) Consensus on the competencies required for public health nutrition workforce development in Europe - the JobNut project. Public Health Nutr 14, 1439-1449.

5. Hawe P, King L, Noort M et al. (1998) Working invisibly: health workers talk about capacity-building in health promotion. Health Promot Int 13, 285-295.

6. Labonte R \& Laverack G (2001) Capacity building in health promotion, Part 1: for whom? And for what purpose? Crit Public Health 11, 111-127.

7. Shediac-Rizkallah M \& Bone L (1998) Planning for sustainability of community-based health programs: conceptual frameworks and future directions for research, practice and policy. Health Educ Res 13, 87-108.

8. Rifkin S, Muller F \& Bichmann W (1988) Primary health care: on measuring participation. Soc Sci Med 26, 931-940.

9. Polit D \& Hungler B (1999) Nursing Research: Principles and Methods, Gth ed. Philadelphia, PA: Lippincott Williams \& Wilkins.

10. Jones J \& Hunter D (1995) Qualitative research: consensus methods for medical and health services research. BMJ 311, 376-380.
11. Grbich C (1999) Qualitative Research in Health: An Introduction. St Leonards, NSW: Allen \& Unwin Pty Ltd.

12. Rowe G \& Wright G (1999) The Delphi technique as a forecasting tool: issues and analysis. Int J Forecasting $\mathbf{1 5}$, 353-375.

13. Duffield C (1993) The Delphi technique: a comparison of results obtained using two expert panels. Int J Nurs Stud $\mathbf{3 0}$, 227-237.

14. Hughes R (2003) Definitions for public health nutrition: a developing consensus. Public Health Nutr 6, 615-620.

15. Hughes R (2004) Competencies for effective public health nutrition practice: a developing consensus. Public Health Nutr 7, 683-691.

16. Schulz V, Kozell K, Biondo P et al. (2009) The malignant wound assessment tool: a validation study using a Delphi approach. Palliat Med 23, 266-273.

17. Palisano R, Rosenbaum P, Bartlett D et al. (2008) Content validity of the expanded and revised Gross Motor Function Classification System. Dev Med Child Neurol 50, 744-750.

18. Hatcher T \& Colton S (2007) Using the internet to improve HRD research: the case of the web-based Delphi research technique to achieve content validity of an HRD-oriented measurement. J Eur Ind Training 31, 570-587.

19. Laverack $G$ (2001) An identification and interpretation of the organizational aspects of community empowerment. Community Dev J 36, 134-145.

20. Bush R, Dower J \& Mutch A (2002) Community Capacity Index: Version 2. Brisbane, QLD: Centre for Primary Health Care, The University of Queensland.

21. NSW Health (2001) A Framework for Building Capacity to Improve Health. Sydney, NSW: NSW Health Department.

22. Goodman R, Speers M, McLeroy K et al. (1998) Identifying and defining the dimensions of community capacity to provide a basis for measurement. Health Educ Behav 25 , 258-278.

23. Liamputtong P (2013) Research Methods in Health, 2nd ed. Melbourne, VIC: Oxford University Press.

24. Hughes R (2004) Enumerating and profiling the Australian public health nutrition workforce. Nutr Diet 61, 162-171.

25. Fox A, Chenhall C, Traynor M et al. (2008) Public health nutrition practice in Canada: a situational assessment. Public Health Nutr 11, 773-781.

26. Haughton B \& George A (2008) The Public Health Nutrition workforce and its future challenges: the US experience. Public Health Nutr 11, 782-791.

27. Landman JP \& Wootton SA (2007) Professional regulation of nutritionists: where are we now? Proc Nutr Soc 66, 269-276.

28. Judd R (1972) Use of Delphi methods in higher education. Tech Forecast Soc Change 4, 173-186.

29. Sanigorski A, Bell A, Kremer P et al. (2008) Reducing unhealthy weight gain in children through community capacity-building: resutls of a quasi-experimental intervention program, Be Active Eat Well. Int J Obes (Lond) 32, 1060-1067.

30. Coitinho D, Monteiro C \& Popkin B (2002) What Brazil is doing to promote healthy diets and active lifestyles. Public Health Nutr 5, 263-267.

31. de Groot F, Robertson N, Swinburn B et al. (2010) Increasing community capacity to prevent childhood obesity: challenges, lessons learned and results from the Romp \& Chomp intervention. BMC Public Health 10, 522.

32. Hughes R (2003) A conceptual framework for intelligencebased public health nutrition workforce development. Public Health Nutr 6, 599-605.

33. Mitchell S \& Shortell S (2000) The governance and management of effective community health partnerships: a typology for research, policy, and practice. Milbank $Q \mathbf{7 8}$, 241-289.

34. Chaskin R, Brown P, Venkatesh S et al. (2001) Building Community Capacity. New York: Aldine De Gruyter. 